\title{
EARLY INTRODUCTION OF PARENTAL NUTRITION IMPROVES HEAD CIRCUMFERENCE IN PREMATURE NEONATES < 28 WEEKS GESTATION
}

\author{
J. Gasson, S. Pradeep, D. Sharkey \\ Division of Academic Child Health, University of Nottingham, Nottingham, UK
}

Background: Commencement of early nutrition in preterm infants can reduce the nutritional deficit and improve later neurodevelopmental outcomes. In 2006, we introduced 'starter' bags of parental nutrition (PN) to commence immediately after birth in infants $<28$ weeks gestation. Prior to this, PN commenced later following a period of intravenous dextrose.

Aims: Establish if early commencement of PN improves growth outcomes in preterm infants $<28$ weeks gestation.

Methods: Retrospective case note review of all surviving babies $<28$ weeks gestation admitted, within 48 hours of birth, to 2 tertiary NICUs. Infants were grouped according to late (2000 to 2004) or early (2006 to 2008) commencement of PN and growth data collected at discharge, 1 and 2 years of age. Growth outcomes are defined as $\mathrm{Z}$ score change from birth (mean $\pm \mathrm{SEM})$.

Results: There were no differences in demographic details between early or late PN groups (gestation, birth weight, postnatal steroids, ventilation, NEC, IVH). PN was commenced almost 2 days earlier in the early PN group. There were no differences between $\mathrm{Z}$ scores for weight but OFC was significantly better in the early $\mathrm{PN}$ group $(\mathrm{P}<0.05$, see figure $)$

\section{$Z$ score change of OFC from birth to 2 years}

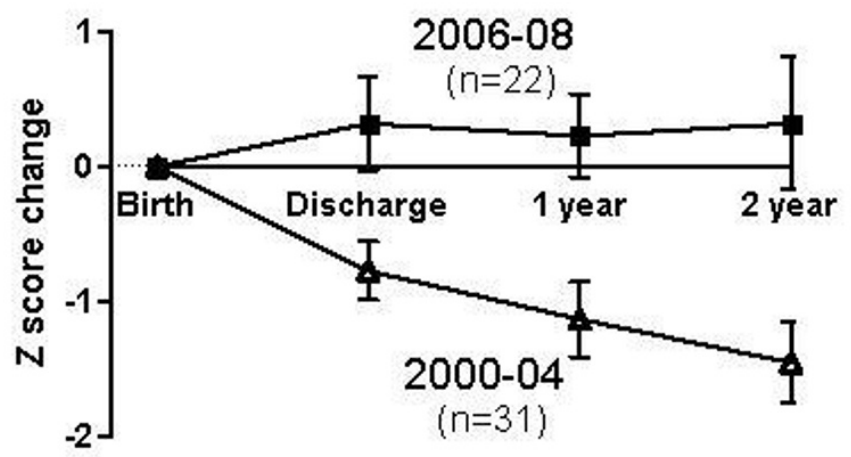

[Figure]

Conclusion: Our data suggests that early commencement of PN reduces nutritional deficits and improves head growth. Despite the limitations of this study, improvements in our nutritional practice, has increased head growth following discharge. 